\title{
Investigation of the functional single-nucleotide polymorphisms in the $B C R P$ transporter and susceptibility to colorectal cancer
}

\author{
FATIH M. SARI ${ }^{1}$, HAKAN T. YANAR ${ }^{2}$ and GUL OZHAN ${ }^{1}$ \\ ${ }^{1}$ Department of Pharmaceutical Toxicology, Faculty of Pharmacy, Istanbul University, Istanbul 34116; \\ ${ }^{2}$ Department of General Surgery, Faculty of Medicine, Istanbul University, Istanbul 34390, Turkey
}

Received October 14, 2014; Accepted October 21, 2014

DOI: 10.3892/br.2014.383

\begin{abstract}
Breast cancer resistance protein $(B C R P)$ protects tissues by actively transporting xenobiotics and their metabolites out of the cells. $B C R P$ is expressed in the apical membrane of normal intestinal and colonic epithelium. The $B C R P$ substrates include a number of structurally unrelated compounds, such as drugs, pesticides, carcinogens and endogenous compounds. Although the functional and common $B C R P$ alleles, $34 \mathrm{G}>\mathrm{A}$ and $421 \mathrm{C}>\mathrm{A}$, are shown to vary by ethnicity, their potential mechanism has not been adequately described with regards to affecting the susceptibility to colorectal cancer. The present study aimed to evaluate the effects of the $B C R P$ variants on the susceptibility to colorectal cancer and to predict the individual responses to xenobiotics transferred by $B C R P$. BCRP $421 \mathrm{C}>\mathrm{A}$ was significantly associated with the colorectal cancer risk (odds ratio, 16.12; $\mathrm{P}=0.005$ ). These findings are the first results of $B C R P$ allele distributions in the Turkish population and provide an understanding of the correlation between therapeutic approaches and etiology of colorectal cancer.
\end{abstract}

\section{Introduction}

Colorectal cancer, one of the most challenging health issues today, is a multi-factorial disease that results from complex interactions between environmental and genetic factors (1-3). A number of studies have indicated that colorectal cancer is a result of xenobiotic exposure, such as those taken up with diet, cigarette-smoke, drugs and alcohol. The xenobiotics causing colorectal cancer development enter the body as (pro)carcinogens via transporters and are either activated to carcinogens or eliminated by various enzymes $(3,4)$. The genetic background controls these toxicokinetic-associated

Correspondence to: Dr Gul Ozhan, Department of Pharmaceutical Toxicology, Faculty of Pharmacy, Istanbul University, Beyazit, Istanbul 34116, Turkey

E-mail: gulozhan@istanbul.edu.tr

Key words: BCRP variants, genetic polymorphisms, colorectal cancer proteins and enzymes. The genetic variables, ranging from single-nucleotide polymorphism (SNP) to major chromosomal aberration may increase the contribution to the development of cancer $(2,5)$.

The adenosine triphosphate-binding cassette (ABC) transporter superfamily is one of the largest and most broadly-expressed, with the majority of proteins responsible for the active transport of a wide variety of compounds across extra- and intracellular membranes (6-8). The breast cancer resistance protein $(B C R P)$ belongs to a subfamily of the $\mathrm{ABC}$ transporters and is expressed in the placenta, liver, brain, small intestine and breast in humans $(9,10) . B C R P$ is predominantly found in the liver canalicular membrane and the apical membrane of the intestinal epithelium. Therefore, $B C R P$ transport activity has a critical role in prevention of intestinal absorption and in mediating hepatobiliary excretion of its substrates, including anticancer drugs and carcinogenic xenobiotics (11).

$B C R P$ has undergone systematic screening for SNPs in 90 different ethnic populations. Thus far, $>40$ non-synonymous and synonymous SNPs have been identified in promoter, and exon and intron sequences (12). Two SNPs, 34G $>$ A and $421 \mathrm{C}>\mathrm{A}$, decrease the clearance and/or increase the oral bioavailability of the $B C R P$ substrates due to altered transport function and hindered expression of variant $B C R P$ proteins in the liver and small intestine. The $B C R P 34 \mathrm{G}>\mathrm{A}$ variant (rs2231137), resulting in a Val12Met (V12M) substitution, results in apical plasma membrane dislocalization of $B C R P$ and generates a protein with a significantly reduced ability to transport several drugs/xenobiotics. The BCRP 421C $>\mathrm{A}$ variant (rs2231142), causes a Gln141Lys (Q141K) change, and is associated with low levels of $B C R P$ expression (13).

The potential mechanism of the $B C R P$ variants affecting susceptibility to colorectal cancer remains to be adequately described (3,14-18). However, based on the current evidence, we hypothesize that two functional and common SNPs of $B C R P$, namely $34 \mathrm{G}>\mathrm{A}$ and $421 \mathrm{C}>\mathrm{A}$, should potentially have an effect on the susceptibility and prognosis of disease. In the present study, the first aim was to determine the significance of $B C R P$ in the development of colorectal cancer. The second aim was to predict the individual response of the Turkish population to xenobiotics transferred by $B C R P$, as the $B C R P$ alleles, observed in various populations and sub-populations, have not been investigated in the Turkish population. 


\section{Materials and methods}

Subjects. To examine the association between the BCRP gene polymorphisms and the susceptibility to colorectal cancer, a case-control study was conducted in the Turkish population. The study was approved by the Ethics Committee of Istanbul University (2011/87-555; Istanbul, Turkey) and all the participants provided written informed consent. The study was conducted in accordance with the Declaration of Helsinki (1964). Blood samples were collected from 108 patients with colorectal cancer and 157 healthy volunteers that were admitted to the Hospital of Istanbul University and Bagcilar Training and Research Hospital (Istanbul, Turkey) during the same period (between 2011 and 2013). The criteria for diagnosis of colorectal cancer were a clinical history consistent with the disease, positive colonoscopic results and routine laboratory analysis parameters. The histopathological examinations were evaluated according to the established clinical criteria (19). The controls were hospital patients with various diagnoses (eye, pulmonary and cardiovascular diseases, and neurological disorders) who have never had cancer. For all the subjects, gender, age and body mass index (BMI, $\mathrm{kg} / \mathrm{cm}^{2}$ ) were recorded. There were no significant differences for gender, age and BMI between case ( 48 females and 61 males; mean age, $43.3 \pm 16.0$ years; mean BMI, $\left.26.0 \pm 4.7 \mathrm{~kg} / \mathrm{cm}^{2}\right)$ and control ( 87 females and 75 males; mean age, $51.2 \pm 17.0$ years; mean BMI, $26.7 \pm 5.3 \mathrm{~kg} / \mathrm{cm}^{2}$ ) groups, suggesting that the matching based on these two variables was adequate $(\mathrm{P}>0.05)$.

Genotyping of the BCRP variants. Venous blood was drawn from subjects and genomic DNA was extracted from whole blood using standard phenol-chloroform extraction protocols. Genotyping of BCRP $34 \mathrm{G}>\mathrm{A}$ and $421 \mathrm{C}>\mathrm{A}$ variants was performed by polymerase chain reaction (PCR)-restriction fragment length polymorphism methods (Table I). The temperature was controlled by a programmable heat block (Gene Amp PCR System 9700; Applied Biosystems, Carlsbad, CA, USA). Restriction enzymes were obtained from New England Biolabs (Hitchin, UK) and Fermentas (Vilnius, Lithuania). All the other molecular biological chemicals were obtained from Fermentas and Sigma-Aldrich (St. Louis, MO, USA). Genotyping was performed blinded to case-control status. A 10\% random sample was genotyped twice for quality assurance, which yielded $100 \%$ concordance.

Statistical analysis. The Hardy-Weinberg equilibrium was investigated using the $\chi^{2}$ test. For the analyses of the genotype frequencies, the wild-type category (chosen either as the most common wild-type frequency or arbitrarily if the two alleles showed similar frequencies) was used as the reference group. The odds ratios (ORs) and $95 \%$ confidence intervals (CIs) were estimated based on the comparison of the genotypes between the patients with colorectal cancer and the healthy controls. Statistical analysis was implemented using the Statistical Package for Social Sciences program (version 17.0; SPSS, Inc., Chicago, IL, USA). A two-sided $\mathrm{P}<0.05$ was considered to indicate a statistically significant difference.

\section{Results}

$B R C P$ variants. The genotype distributions did not significantly deviate from the Hardy-Weinberg equilibrium in the cases and controls for any of the examined SNPs, BCRP $34 \mathrm{G}>\mathrm{A}$ and $421 C>A$. Subsequently, the differences between the cases and controls regarding the distribution of genotype was analyzed. The BCRP 34A recessive allele frequencies were 0.064 and 0.111 in the controls and cases, respectively. The $B C R P$ 421 A recessive allele frequencies were 0.139 and 0.013 in the controls and cases, respectively. BCRP 421AA genotypes were not observed in the controls and cases (Table II). In all the samples $(\mathrm{n}=265)$, the major allelic frequencies for $B C R P$ $34 \mathrm{G}$ and $421 \mathrm{C}$ were observed as 0.922 and 0.940 , respectively (Table II).

In the study, it was observed that $B C R P 421 C>A$ was statistically significantly associated with the colorectal cancer risk. The association was observed with $B C R P 421 \mathrm{C}>\mathrm{A}(\mathrm{P}=0.0005)$; in particular, patients carrying the $A$ allele compared to patients carrying the $C$ allele had a significantly higher risk of disease (OR, 16.12; 95\% CI, 2.08-125.1) (Table II). To confirm the genotyping results for this variants, which is associated with colorectal cancer, the selected PCR-amplified DNA samples $(n=4$, for each genotype in the cases and controls) were examined by DNA sequencing and the results were also $100 \%$ concordant. By contrast, genotype distribution of $B C R P$ $34 \mathrm{G}>\mathrm{A}$ in the cases and controls did not significantly differ and thus the polymorphism was not associated with the risk of colorectal cancer (OR, 0.52; 95\% CI, 0.18-1.46; P=0.204) (Table II).

\section{Discussion}

$B C R P$ plays an important role in preventing intestinal absorption, mediating hepatobiliary excretion and controlling the cellular export for its substrates as it actively transports a wide-spectrum of substrates, ranging from chemotherapeutic agents to carcinogenic xenobiotics (20-25). The differential xenobiotic metabolism, which is due to variations in the transporter molecules, may affect the risk of certain types of cancers (26-31). In certain studies, a possible role of transporter deficiencies was indicated in the susceptibility for colon carcinoma $(14,18,32)$. Therefore, $34 \mathrm{G}>\mathrm{A}$ and $421 \mathrm{C}>\mathrm{A}$ polymorphisms in the $B C R P$ gene were studied as they are the most common between the different ethnic groups (33). $421 \mathrm{C}>\mathrm{A}$ is associated with the decreased expression of the $B C R P$ protein (34) and $34 \mathrm{G}>\mathrm{A}$ is associated with decreased $B C R P$ transporter activity (35).

Dietrich et al (3) analyzed BCRP expression in 29 adenomas from 21 patients and eight adenomas from four mice. The study reported that $B C R P$ was significantly downregulated in human colorectal adenomas (to $28 \pm 35 \%$ of the adjacent healthy tissue), which may reduce the xenobiotic resistance of cells that are already neoplastic, resulting in acceleration of carcinoma development. Gupta et al (16) reported that BCRP mRNA was present in normal colorectal tissue, but showed a 6-fold decrease in cancerous tissues. The study suggested that decreased $B C R P$ expression may have a role in carcinogenesis by permitting the accumulation of genotoxins and overproduction of nitric oxide, and that downregulation of $B C R P$ was likely to be a common 
Table I. Details of methodology used in genotyping by polymerase chain reaction analysis.

\begin{tabular}{llcc}
\hline BCRP SNP & \multicolumn{1}{c}{ Primer sequence } & $\begin{array}{c}\text { Annealing } \\
\text { temperature, }{ }^{\circ} \mathrm{C}\end{array}$ & $\begin{array}{c}\text { Restriction } \\
\text { enzyme }\end{array}$ \\
\hline 421C $>$ A & $\begin{array}{l}\text { 5'-GTTGTGATGGGCACTCTGATGGT-3' } \\
\text { 5'-AACAATGAGAAAAGTGGCTTG-3' }\end{array}$ & 62.4 & MseI \\
34G $>$ A & 5'-CAGTAATGTCGAAGTTTTTATCGCA-3' & 61.2 & BsrDI \\
& 5'-AAATGTTCATAGCCAGTTTCTTGGA-3' & & $291,261,30$ \\
\hline
\end{tabular}

SNP, single nucleotide polymorphism; BCRP, breast cancer resistance protein; bp, base pair.

Table II. Allele frequencies of breast cancer resistance protein $(B C R P)$ polymorphisms in the healthy subjects and the patients with colorectal cancer.

\begin{tabular}{|c|c|c|c|c|c|c|c|}
\hline \multirow[t]{3}{*}{ Subject (n) } & \multicolumn{3}{|c|}{ Genotype frequencies, $\mathrm{n}(\%)$} & \multicolumn{2}{|c|}{ Allele frequency } & \multirow[t]{2}{*}{ OR $(95 \% \mathrm{CI})$} & \multirow[t]{2}{*}{ P-value } \\
\hline & \multicolumn{5}{|c|}{$B C R P 421 \mathrm{C}>\mathrm{A}$} & & \\
\hline & $\mathrm{CC}$ & $\mathrm{CA}$ & AA & $\mathrm{C}$ & A & & \\
\hline Cases (108) & $0(0)$ & $30(27.8)$ & $78(72.2)$ & 0.139 & 0.861 & C vs. A & 0.0005 \\
\hline \multirow[t]{3}{*}{ Controls (157) } & $0(0)$ & $2(1.3)$ & $155(98.7)$ & 0.013 & 0.987 & $16.12(2.08-125.1)$ & \\
\hline & \multicolumn{5}{|c|}{$B C R P 34 \mathrm{G}>\mathrm{A}$} & & \\
\hline & GG & GA & AA & G & A & & \\
\hline Cases (108) & 85 (78.7) & $22(20.4)$ & $1(0.9)$ & 0.889 & 0.111 & G vs. A & 0.204 \\
\hline Controls (157) & 138 (87.9) & $18(11.5)$ & $1(0.6)$ & 0.936 & 0.064 & $0.52(0.18-1.46)$ & \\
\hline
\end{tabular}

OR, odds ratio; CI, confidence interval.

occurrence in several tissues. Liu et al (36) believed that BCRP expression may be different in the various stages of carcinogenesis. In the early stage of carcinogenesis, $B C R P$ may be downregulated to permit the accumulation of genotoxins and nitric oxide overproduction. However, in the more advanced stages of carcinogenesis, it may be upregulated to protect the cancerous cells by expelling the chemotherapeutic drugs. The study concluded that $B C R P$ was important in the progression and metastasis of colorectal cancer and that it may be a novel target for cancer therapy. Ebert et al (15) observed that BCRP was involved in the transport of the metabolically formed sulphate and glucuronide conjugates of the carcinogen benzo[a] pyrene and related food-associated polycyclic aromatic hydrocarbon (PAH) in the Caco-2 human intestinal cell line. The study also reported that $B C R P$ gene regulation was most likely mediated via an Ah receptor-dependent pathway.

$\mathrm{Hu}$ et al (37) investigated the association between the risk and survival of diffuse large B-cell lymphoma (DLBCL) and the two $B C R P$ variants, $421 \mathrm{C}>\mathrm{A}$ and $34 \mathrm{G}>\mathrm{A}$. An increased risk of DLBCL was associated with the $421 \mathrm{~A}$ allele $(\mathrm{P}=0.042)$ and a worse survival was associated with the 34AA genotypes (hazard ratio, 3.69) in 156 DLBCL patients and 376 control subjects. In another study, a Japanese group found that the $B C R P$ 421CC homozygotes were at a higher risk to develop non-papillary renal cell carcinoma (30). In the present study,
BCRP 421C $>$ A was significantly associated with the colorectal cancer risk $(\mathrm{OR}=16.12,95 \% \mathrm{CI}$ : 2.08-125.1), whereas distribution of the $B C R P 34 \mathrm{G}>\mathrm{A}$ genotypes did not significantly differ in the case and control groups $(\mathrm{P}=0.204)$. In contrast to the present study results, Andersen et al (1) found no association between the $B C R P$ genotypes and risk of colorectal cancer, and no interaction between $B C R P 421 C>\mathrm{A}$ and meat, smoking or nonsteroidal anti-inflammatory drugs. In the study by Zamber et al (33), there was no significant correlation between the $421 \mathrm{C}>\mathrm{A}$ variant and $B C R P$ expression in human intestinal samples.

The previous studies have shown significant differences in the genotype frequencies of $34 \mathrm{G}>\mathrm{A}$ and $421 \mathrm{C}>\mathrm{A}$ among different ethnic populations. For $34 \mathrm{G}>\mathrm{A}$, the Han Chinese population appears to exhibit the highest frequency (34\%), whereas the variant allele is extremely rare in the sub-Sahara African populations $(<1 \%)$ and occurs at a relatively low frequency in African-American and Caucasian populations in the United States (5 and 12\%, respectively) (38). The allelic frequencies in Mexican-Indian, Mexican and Hispanic populations were 90, 10 and 40\%, respectively (33). The 421C>A allele appears to be extremely common in Asian populations, with allelic frequencies reported between 27 and 34\% (39-41). The 421C $>$ A allele is the most prevalent allele in Japanese and Chinese populations with an allelic frequency of $35 \%(40,42)$. 
In contrast, the $421 \mathrm{C}>\mathrm{A}$ allele is rare in sub-Sahara African and African-American populations, with a frequency of $5 \%(39,41)$. The frequency in Caucasian populations is $\sim 10 \%(35,41,43,44)$. For the two polymorphisms investigated in the present study, there was no prior information regarding their distribution in the Turkish population. The study showed that the frequencies of the Turkish population who exhibited the 421A and 34A alleles were 6 and $8.3 \%$, respectively. Regarding these results, approximately one in ten Turkish subjects may express low amounts of $B C R P$ and Turkish people may be vulnerable when assessing the sensitivity of the population to therapeutic drugs and environmental toxicants.

In conclusion, it is widely believed that the $B C R P$ transporters play a crucial role in detoxification and protection against xenobiotic substances. There may be cases in which the $B C R P$ gene variants may be more or less important contributors regarding the sensitivity to cancer-inducing or -promoting compounds, by interacting differently to the environmental factors. These findings assure further investigations with regards to the association of the $B C R P$ SNPs with with susceptibility and the clinical outcome of cancer. To the best of our knowledge, this is the first study to report the association between the two polymorphisms and colorectal cancer. Therefore, the results of the present study suggest that the findings contribute to the literature, even when the small number of subjects examined with the association may have limited the power to detect the effects of the gene on the colorectal cancer risk.

\section{Acknowledgements}

The authors wish to thank all the subjects that volunteered to participate. The study was supported by the Research Fund of Istanbul University (grant no. 24985/42545).

\section{References}

1. Andersen V, Ostergaard M, Christensen J, et al: Polymorphisms in the xenobiotic transporter Multidrug Resistance 1 (MDR1) and interaction with meat intake in relation to risk of colorectal cancer in a Danish prospective case-cohort study. BMC Cancer 9: 407, 2009.

2. Chen P, Zhao L, Zou P, et al: The contribution of the ABCG2 C421A polymorphism to cancer susceptibility: A meta-analysis of the current literature. BMC Cancer 12: 383, 2012.

3. Dietrich CG, Vehr AK, Martin IV, et al: Downregulation of breast cancer resistance protein in colon adenomas reduces cellular xenobiotic resistance and leads to accumulation of a food-derived carcinogen. Int J Cancer 129: 546-552, 2011.

4. Guengerich FP: Metabolism of chemical carcinogens. Carcinogenesis 21: 345-351, 2000.

5. Shiloh Y: ATM and related protein kinases: Safeguarding genome integrity. Nat Rev Cancer 3: 155-168, 2003.

6. Dietrich CG, Geier A, Oude Elferink RP: ABC of oral bioavailability: Transporters as gatekeepers in the gut. Gut 52: 1788-1795, 2003 .

7. Klein I, Sarkadi B and Varadi A: An inventory of the human ABC proteins. Biochim Biophys Acta 1461: 237-262, 1999.

8. Velamakanni S, Wei SL, Janvilisri T, et al: ABCG transporters: Structure, substrate specificities and physiological roles: A brief overview. J Bioenerg Biomembr 39: 465-471, 2007.

9. Allikmets R, Schriml LM, Hutchinson A, et al: A human placenta-specific ATP-binding cassette gene (ABCP) on chromosome $4 \mathrm{q} 22$ that is involved in multidrug resistance. Cancer Res 58: 5337-5339, 1998.

10. Doyle LA, Yang W, Abruzzo LV, et al: A multidrug resistance transporter from human MCF-7 breast cancer cells. Proc Natl Acad Sci USA 95: 15665-15670, 1998.
11. Isshiki M, Umezawa $\mathrm{K}$ and Tamura $\mathrm{H}$ : Coffee induces breast cancer resistance protein expression in Caco-2 cells. Biol Pharm Bull 34: 1624-1627, 2011.

12. Lockhart AC, Tirona RG and Kim RB: Pharmacogenetics of ATP-binding cassette transporters in cancer and chemotherapy. Mol Cancer Ther 2: 685-698, 2003.

13. Staud F and Pavek P: Breast cancer resistance protein (BCRP/ABCG2). Int J Biochem Cell Biol 37: 720-725, 2005.

14. Campa D, Pardini B, Naccarati A, et al: A gene-wide investigation on polymorphisms in the ABCG2/BRCP transporter and susceptibility to colorectal cancer. Mutat Res 645: 56-60, 2008.

15. Ebert B, Seidel A and Lampen A: Identification of BCRP as transporter of benzo[a]pyrene conjugates metabolically formed in Caco-2 cells and its induction by Ah-receptor agonists. Carcinogenesis 26: 1754-1763, 2005.

16. Gupta N, Martin PM, Miyauchi S, et al: Down-regulation of BCRP/ABCG2 in colorectal and cervical cancer. Biochem Biophys Res Commun 343: 571-577, 2006.

17. Jonker JW, Buitelaar M, Wagenaar E, et al: The breast cancer resistance protein protects against a major chlorophyll-derived dietary phototoxin and protoporphyria. Proc Natl Acad Sci USA 99: 15649-15654, 2002.

18. Pavek P, Merino G, Wagenaar E, et al: Human breast cancer resistance protein: Interactions with steroid drugs, hormones, the dietary carcinogen 2-amino-1-methyl-6-phenylimidazo(4,5-b) pyridine, and transport of cimetidine. J Pharmacol Exp Ther 312: 144-152, 2005.

19. Compton CC and Greene FL: The staging of colorectal cancer: 2004 and beyond. CA Cancer J Clin 54: 295-308, 2004.

20. Krishnamurthy P and Schuetz JD: Role of ABCG2/BCRP in biology and medicine. Annu Rev Pharmacol Toxicol 46: 381-410, 2006.

21. Maliepaard M, Scheffer GL, Faneyte IF, et al: Subcellular localization and distribution of the breast cancer resistance protein transporter in normal human tissues. Cancer Res 61: 3458-3464, 2001.

22. Mao Q and Unadkat JD: Role of the breast cancer resistance protein (ABCG2) in drug transport. AAPS J 7: E118-E133, 2005.

23. Muller P, Asher N, Heled M, et al: Polymorphisms in transporter and phase II metabolism genes as potential modifiers of the predisposition to and treatment outcome of de novo acute myeloid leukemia in Israeli ethnic groups. Leuk Res 32: 919-929, 2008.

24. Sarkadi B, Ozvegy-Laczka C, Nemet K, et al: ABCG2 - a transporter for all seasons. FEBS Lett 567: 116-120, 2004.

25. Schinkel AH and Jonker JW: Mammalian drug efflux transporters of the ATP binding cassette (ABC) family: An overview. Adv Drug Deliv Rev 55: 3-29, 2003.

26. Dai D, Zeldin DC, Blaisdell JA, et al: Polymorphisms in human CYP2C8 decrease metabolism of the anticancer drug paclitaxel and arachidonic acid. Pharmacogenetics 11: 597-607, 2001.

27. Eisenblatter T and Galla HJ: A new multidrug resistance protein at the blood-brain barrier. Biochem Biophys Res Commun 293: 1273-1278, 2002.

28. Jonker JW, Smit JW, Brinkhuis RF, et al: Role of breast cancer resistance protein in the bioavailability and fetal penetration of topotecan. J Natl Cancer Inst 92: 1651-1656, 2000.

29. Jonker JW, Merino G, Musters S, et al: The breast cancer resistance protein BCRP (ABCG2) concentrates drugs and carcinogenic xenotoxins into milk. Nat Med 11: 127-129, 2005.

30. Korenaga Y, Naito K, Okayama N, et al: Association of the BCRP C421A polymorphism with nonpapillary renal cell carcinoma. Int J Cancer 117: 431-434, 2005.

31. Kruijtzer CM, Beijnen JH, Rosing $\mathrm{H}$, et al: Increased oral bioavailability of topotecan in combination with the breast cancer resistance protein and P-glycoprotein inhibitor GF120918. J Clin Oncol 20: 2943-2950, 2002.

32. Haimeur A, Conseil G, Deeley RG, et al: The MRP-related and BCRP/ABCG2 multidrug resistance proteins: Biology, substrate specificity and regulation. Curr Drug Metab 5: 21-53, 2004.

33. Zamber CP, Lamba JK, Yasuda K, et al: Natural allelic variants of breast cancer resistance protein (BCRP) and their relationship to BCRP expression in human intestine. Pharmacogenetics 13: 19-28, 2003.

34. Kondo C, Suzuki H, Itoda M, et al: Functional analysis of SNPs variants of BCRP/ABCG2. Pharm Res 21: 1895-1903, 2004.

35. Mizuarai S, Aozasa N and Kotani H: Single nucleotide polymorphisms result in impaired membrane localization and reduced ATPase activity in multidrug transporter ABCG2. Int J Cancer 109: 238-246, 2004. 
36. Liu HG, Pan YF, You J, et al: Expression of ABCG2 and its significance in colorectal cancer. Asian Pac J Cancer Prev 11: 845-848, 2010

37. Hu LL, Wang XX, Chen X, et al: BCRP gene polymorphisms are associated with susceptibility and survival of diffuse large B-cell lymphoma. Carcinogenesis 28: 1740-1744, 2007.

38. Pollex EK, Anger G, Hutson J, et al: Breast cancer resistance protein (BCRP)-mediated glyburide transport: Effect of the C421A/Q141K BCRP single-nucleotide polymorphism. Drug Met Dispos 38: 740-744, 2010.

39. de Jong FA, Marsh S, Mathijssen RH, et al: ABCG2 pharmacogenetics: Ethnic differences in allele frequency and assessment of influence on irinotecan disposition. Clin Cancer Res 10: 5889-5894, 2004.

40. Imai Y, Nakane M, Kage K, et al: C421 A polymorphism in the human breast cancer resistance protein gene is associated with low expression of Q141K protein and low-level drug resistance. Mol Cancer Ther 1: 611-616, 2002.
41. Kobayashi D, Ieiri I, Hirota T, et al: Functional assessment of ABCG2 (BCRP) gene polymorphisms to protein expression in human placenta. Drug Metab Dispos 33: 94-101, 2005.

42. Itoda M, Saito Y, Shirao K, et al: Eight novel single nucleotide polymorphisms in ABCG2/BCRP in Japanese cancer patients administered irinotecan. Drug Metab Pharmacokinet 18: 212-217, 2003.

43. Backstrom G, Taipalensuu J, Melhus H, et al: Genetic variation in the ATP-binding cassette transporter gene ABCG2 (BCRP) in a Swedish population. Eur J Pharm Sci 18: 359-364, 2003.

44. Noguchi K, Katayama K, Mitsuhashi J, et al: Functions of the breast cancer resistance protein (BCRP/ABCG2) in chemotherapy. Adv Drug Deliv Rev 61: 26-33, 2009. 